\title{
Employing Weather-Based Disease and Machine Learning Techniques for Optimal Control of Septoria Leaf Blotch and Stripe Rust in Wheat
}

\author{
Moussa El Jarroudi ${ }^{1(\bowtie)}$, Rachid Lahlali ${ }^{2}$, Haifa El Jarroudi ${ }^{3}$, \\ Bernard Tychon $^{1}$, Alexandre Belleflamme ${ }^{4}$, Jürgen Junk ${ }^{5}$, \\ Antoine Denis ${ }^{1}$, Mustapha El Jarroudi ${ }^{3}$, and Louis Kouadio ${ }^{6}$ \\ ${ }^{1}$ Department of Sciences and Environmental Management, \\ University of Liege, Arlon, Belgium \\ meljarroudi@uliege.be \\ 2 Department of Plant Protection, Ecole Nationale d'Agriculture de Meknès, \\ Meknès, Morocco \\ 3 Laboratory of Mathematics and Applications, FST Tanger, \\ Université Abdelmalek Essaâdi, Tétouan, Morocco \\ ${ }^{4}$ Department of Geography, University of Liège, Liege, Belgium \\ ${ }^{5}$ Environmental Research and Innovation, Luxembourg Institute of Science \\ and Technology, Belvaux, Grand-Duché de Luxembourg \\ ${ }^{6}$ Centre for Applied Climate Sciences, University of Southern Queensland, \\ Toowoomba, Australia
}

\begin{abstract}
Septoria tritici blotch (STB) is among the most important crop diseases causing continuous threats to wheat production worldwide. STB epidemics are the outcome of interactions between susceptible host cultivars, favorable environmental conditions, and sufficient quantities of pathogen inoculum. Thus, to determine whether fungicide sprays should be applied to prevent the risk of epidemics that might otherwise lead to yield loss, weatherbased systems as stand-alone or combined with other disease or agronomic variables have been implemented in decision-support systems (DSS). Given the economic importance of wheat in Morocco and increasing concerns caused by fungal plant pathogens in wheat-growing regions, DSS integrating a disease risk model would help to limit potentially harmful side effects of fungicide applications while ensuring economic benefits. Here we describe the use of an artificial intelligence algorithm, i.e. the artificial neural network, within a weatherbased modelling approach to predict the progress of STB in wheat in Luxembourg. The reproducibility of area-specific modelling approaches is often a hurdle for their application in operational disease warning system at a regional scale. Hence, we explore the potential of coupling artificial intelligence algorithms with weather-based model for predicting in-season progress of a major economically important fungal disease - wheat stripe rust - in selected wheatproducing regions in Morocco.
\end{abstract}




\section{Introduction}

Machine learning (ML) has become a paramount topic in research and industry, with new algorithms being developed and applied in several and various fields. ML encompasses statistical methods that learn to identify patterns in complex datasets. Agriculture is critically important to the economy of many countries worldwide. In the agricultural research, ML techniques are used for various purposes including plant stress phenotyping, identification and prediction of crop diseases (Kranth et al. 2018; Sperschneider 2019; Yang and Guo 2017). Compared to statistical models, ML techniques focus on data themselves and emphasize the performance of certain tasks. Recently, technological methods have been designed for the identification of plants and detection of their diseases in order to meet the new challenges faced by farmers and their learning needs (Prasad et al. 2017).

Wheat is one of the top three staple foods in the world, next to rice and maize (FAO 2018). To protect wheat crop against plant diseases, reliable and timely information on these diseases epidemics are crucial for optimizing the use of fungicides while ensuring economic benefits. Decision-support systems (DSS) based on plant disease forecast models are increasingly used in integrated disease management programs (Verreet et al. 2000; Wegulo et al. 2011; El Jarroudi et al. 2015). Plant disease epidemics of fungal origin result from the interaction between the pathogens, presence of susceptible hosts, and favorable meteorological conditions. Meteorological variables are most often the data used as inputs of disease forecasting models for fungal diseases of wheat (Triticum aestivum L. and Triticum turgidum ssp. Durum). Meteorological variables are most often the data used as inputs of disease forecasting models for fungal diseases, with air temperature, relative humidity, and rainfall being by far the most important. Over the past decades, continuous studies have been performed to investigate the interactions between plant immune response and pathogens. The development of ML algorithms, as a collection of analytic methods that automate model building process and iteratively learn from data to gain insights without explicitly programing, provides powerful and efficient tools to investigate the optimization of fungicide application using DSS. The overall goal of this paper was to describe the use of an artificial intelligence algorithm, i.e. the artificial neural network, within a weather-based modelling approach to predict the progress of Septoria tritici blotch (STB, caused by Zymoseptoria tritici (Desm.) Quaedvlieg \& Crous) in wheat in Luxembourg. The reproducibility of area-specific modelling approaches is often a hurdle for their application in operational disease warning system at a regional scale. Hence, we also explored the potential of coupling artificial intelligence algorithms with weather-based model for predicting in-season progress of a major economically important fungal disease - wheat stripe rust - in selected wheat-producing regions in Morocco. 


\section{Predicting the Progress of Septoria Leaf Blotch in Wheat Using Artificial Neural Network (ANN)}

\subsection{Overview of the Decision-Support System Used for Managing Fungicide Applications}

In Luxembourg, a DSS is currently used within a countrywide disease warning system to help wheat growers limit potentially harmful side effects of fungicide applications while ensuring sustainable economic benefits (El Jarroudi et al. 2015; El Jarroudi et al. 2018). STB is among the most economically important plant fungal diseases causing continuous threats to wheat production in Luxembourg. The DSS relies on four weather-based models including the mechanistic PROCULTURE model, which is used to simulate the emergence of the five youngest leaves as well as the availability of $Z$. tritici inoculum to infect those leaves (Moreau and Maraite 1999; El Jarroudi et al. 2009); two threshold-based models for predicting wheat leaf and stripe rusts infection and progress (El Jarroudi et al. 2014; El Jarroudi et al. 2017; Aslanov et al. 2019); and a model for simulating the progress of wheat powdery mildew (El Jarroudi et al. 2011). The model inputs used are hourly meteorological (i.e. maximum and minimum air temperatures, relative humidity, and rainfall) and leaf wetness data, along with observed disease incidence and severity.

To get a continuous spatial coverage of Luxembourg, couple the PROCULTURE model to 12-hourly operational weather forecasts at $1 \mathrm{~km}$ resolution is adopted. Weather forecasts are provided using the Weather Research and Forecasting (WRF) model for Luxembourg. Because the WRF model does not provide leaf wetness directly (Chen and Dudhia 2001), an artificial neural network (ANN) that establishes a link among observations of leaf wetness and meteorological measurements is used to estimate this variable. ANNs can be used to derive a complex nonlinear relationship among (observed) input and output data without one knowing the exact physical interrelationships involved (Lopez et al. 1998).

\subsection{Evaluation of the ANN in Luxembourgish Conditions}

\section{Study Area and Methodology}

The approach of using ANN to estimate leaf wetness periods in wheat was tested at the five sites selected across the key wheat-growing areas in Luxembourg during the 2007 growing season. Four test plots with winter wheat (Burmerange $\left[49^{\circ} 29^{\prime} \mathrm{N}, 6^{\circ} 19^{\prime} \mathrm{E}\right]$, Christnach $\left[49^{\circ} 47^{\prime} \mathrm{N}, 6^{\circ} 16^{\prime} \mathrm{E}\right.$ ], Everlange $\left[49^{\circ} 46^{\prime} \mathrm{N}, 5^{\circ} 57^{\prime} \mathrm{E}\right.$ ], and Reuler $\left[50^{\circ} 03^{\prime} \mathrm{N}, 6^{\circ}\right.$ $\left.02^{\prime} \mathrm{E}\right]$ ) were equipped with automatic weather stations (AWS) and dielectric leaf wetness sensors (LWS) from DECAGON DEVICES were established at each of the study sites. The LWS were set up at $10 \mathrm{~cm}, 30 \mathrm{~cm}, 60 \mathrm{~cm}$ and $120 \mathrm{~cm}$ above the ground. To evaluate whether the sensor's orientation has any influence on the measurements, two sensors were mounted $120 \mathrm{~cm}$ above ground, orientated north and south (Fig. 1).

The sensor's output signal at 5-min temporal resolution can range from 445 raw counts (totally dry) up to 1400 raw counts (totally wet). Following the advice provided 


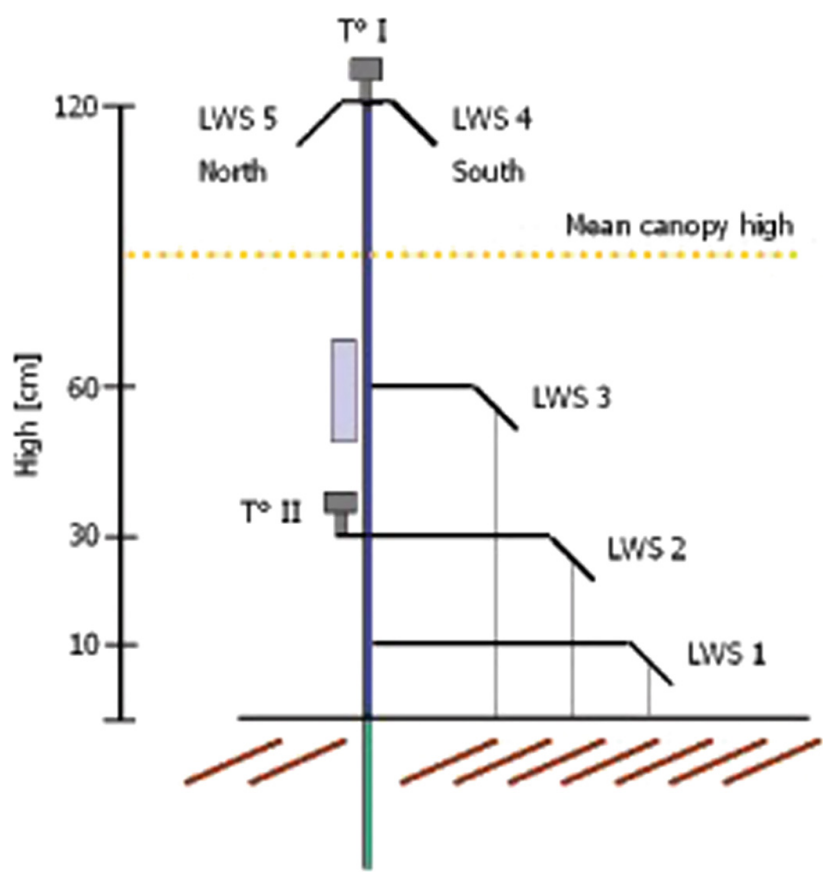

Fig. 1. Set up of air temperature and leaf wetness sensors (Junk et al. 2008).

by DECAGON DEVICES (2006), we used a threshold of 460 raw counts to separate dry from wet conditions. As PROCULTURE model inputs are at hourly intervals we resample the 10-min AWS (averages) as well as the leaf wetness (number of time intervals with wet sensor) measurements to hourly temporal resolutions. Additionally, the saturation vapor pressure $(\mathrm{hPa})$, the absolute humidity $(\mathrm{g} / \mathrm{m} 3)$ as well as the dew point (C) were calculated from the AWS measurements and used as predictors for the neural network (Junk et al. 2008).

Hourly measurements of leaf wetness, air temperature, relative humidity and precipitation, as well as the calculated data of saturated vapour pressure, absolute humidity and the dew point temperature were randomly split into three data sets: $70 \%$ for model training, $15 \%$ for model testing, and $15 \%$ for model validation. The training set determines the adjusted weights between the neurons. During the training period, the network is tested against the test data to determine the accuracy of the derived statistical relationship. The training procedure is stopped, as soon as the mean average error remains unchanged. The ability of the derived ANNs to reproduce the validation data was the verified (Junk et al. 2008).

\section{Results: Satisfactory Performance of ANN in Predicting Leaf Wetness Periods}

Given the poor performance of a multiple linear stepwise forward regression to estimate values of leaf wetness periods $\left(\mathrm{R}^{2}<0.6\right)$, ANN to model the non-linear correlation among the leaf wetness (measured in raw counts) and weather conditions. Different ANN-based models for each study site were calculated. Overall, leaf wetness 
periods were estimated satisfactorily at the study sites in Luxembourg, with $\mathrm{R}^{2}$ up to 0.91. An example of validation results is presented in Fig. 2. Validation results are shown for the test sites at Burmerange (Fig. 2). ANN-models with good performance included air temperature, relative humidity, dew point temperature as well as the hours of the day.

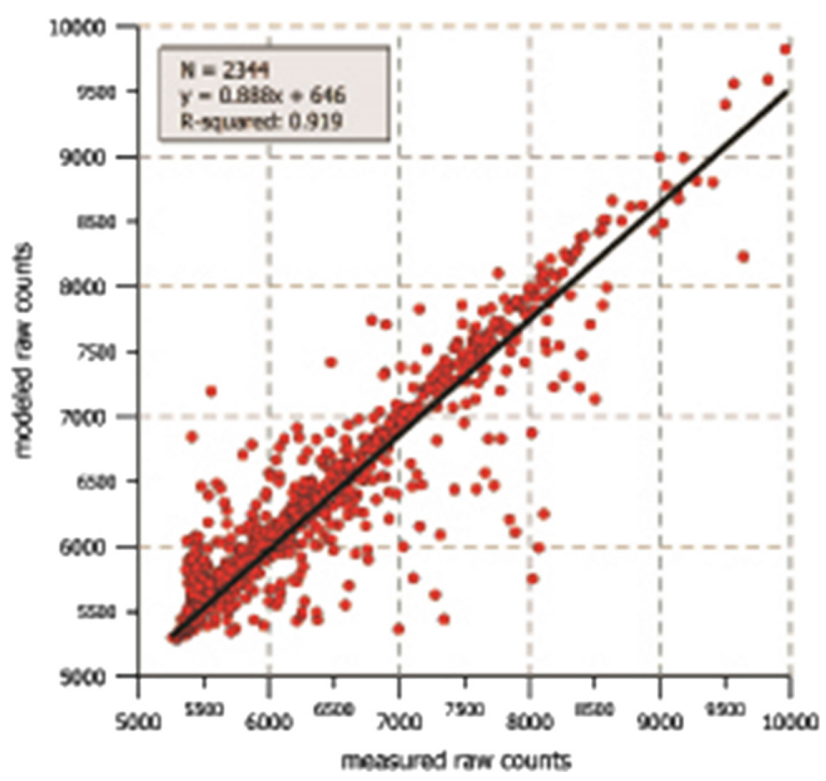

Fig. 2. Scatterplot of ANN-modeled and measured hourly cumulative raw counts of LWS 3 at Burmerange; data from April 13, 2007 to July 19, 2007 (Junk et al. 2008).

Using ANNs we were able to reconstruct longer leaf wetness time series for the past years using only the meteorological data as input variables. Having such capabilities improve the overall performance of the DSS, namely the prediction of STB progress. Moreover, it is now possible to model the duration of leaf wetness for the whole area of Luxembourg and any other country using this approach.

\section{The Way Forward: Employing Machine Learning Techniques for Predicting the Progress of Wheat Stripe Rust in Morocco}

Wheat Stripe rust (WSR, caused by Puccinia striiformis) has recently emerged as a serious threat to wheat production in Morocco (Ali et al. 2017). The 2009-2010 epidemics in North Africa regions occurred due to high frequencies of virulence to important resistance genes like Yr27 (Ali et al. 2017). WSR epidemics occurred in all wheat-growing localities in Morocco during the 2018-2019 period, with variable 
severities depending on the level of crop protection. The detection of new and more aggressive races of $P$. striiformis such as 'Warrior' poses a serious threat to many previously resistant wheat varieties (http://wheatrust.org/; Hovmøller et al. 2015). Symptoms of stripe rust include long stripes of small yellow or orange blister-like lesions called "pustules" (Fig. 3). Apart from cropping of new resistant wheat cultivars, optimal fungicide spraying appear critical to mitigate the adverse impacts on wheat yields of such WSR epidemics.

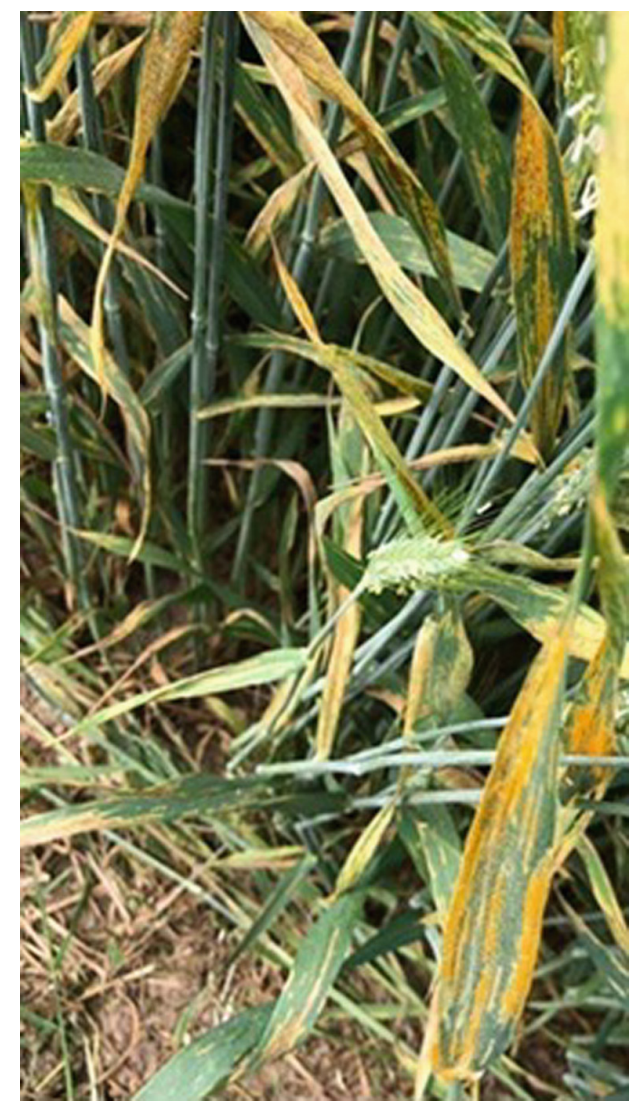

Fig. 3. Symptoms of wheat stripe rust, caused by Puccinia striiformis. (Photo credits: El Jarroudi M.)

WSR epidemics are the outcome of interactions between susceptible host cultivars, favorable environmental conditions, and sufficient quantities of pathogen inoculum (Zadoks 1961; Sache 2000; Hovmoller et al. 2002; Te Beest et al. 2008; El Jarroudi et al. 2017). WSR had been reported in Luxembourg for decades. A threshold-based weather model for predicting the progress of WSR has been successfully applied in Luxembourg (El Jarroudi et al. 2017). Based on weather conditions, infections by 
P. striiformis in commercial wheat fields were predicted in four main Luxembourgish wheat-growing areas with a probability of detection (POD) ranging from 0.91 to 1.00 ; and false alarm ration values ranging from 0.06 to 0.20 (El Jarroudi et al. 2017). This assuming that the inoculum is present in sufficient quantity on fields. Although the modelling approach has to be evaluated in Moroccan conditions, different venues for improving the existing approach can be tested concomitantly (using the same data for model evaluation in Morocco) or separately (using data from Luxembourg). This includes employing ML techniques for in-season prediction of infections by P. striiformis, along with monitoring other plant diseases. Early detection of disease symptoms allows taking adequate control measures to avoid any yield losses. Thus, the majority of studies have employed ML for this purpose using reflectance measurements (e.g., Moshou et al. 2004; Low et al. 2017; Ferentinos 2018) or proximal phenotyping (e.g., Odilbekov et al. 2018). We have started investigating the use of ML techniques such as Random Forest, Multivariate Adaptive Regression Splines, and Naïve Bayes Algorithm as potential candidates to predict infections by $P$. striiformis in wheat. Coupling artificial intelligence algorithms with plant disease models in DSS would definitely help improve sustainable wheat production.

Acknowledgements. We thank the Administration des Services Techniques de l'Agriculture (ASTA) of Luxembourg for financially supporting the project Sentinelle.

\section{References}

Ali, S., Rodriguez-Algaba, J., Thach, T., Sørensen, C.K., Hansen, J.G., Lassen, P., et al.: Yellow rust epidemics worldwide were caused by pathogen races from divergent genetic lineages. Front. Plant Sci. 8, 1057 (2017). https://doi.org/10.3389/fpls.2017.01057

Aslanov, R., El Jarroudi, M., Gollier, M., Pallez-Barthel, M., Beyer, M.: Yellow rust does not like cold winters. But how to find out which temperature and time frames could be decisive in vivo? J. Plant Pathol. 1-8 (2019). https://doi.org/10.1007/s42161-018-00233-y

Chen, F., Dudhia, J.: Coupling an advanced land surface-hydrology model with the Penn StateNCAR MM5 modeling system. Part I: model implementation and sensitivity. Mon. Weather Rev. 129, 569-585 (2001)

DECAGON DEVICES Inc.: Dielectric Leaf Wetness Sensor-Operator's manual, Version 1.0, USA (2006)

El Jarroudi, M., Delfosse, P., Maraite, H., Hoffmann, L., Tychon, B.: Assessing the accuracy of simulation model for Septoria leaf blotch disease progress on winter wheat. Plant Dis. 93, 983-992 (2009)

El Jarroudi, M., Giraud, F., Delfosse, P., Beyer, M., Hoffmann, L., Maraite, H., Tychon, B.: Sitespecific monitoring for disease forecasting in winter wheat. J. Plant Pathol. 93(Suppl. 1), S1.19-S11.20 (2011)

El Jarroudi, M., Kouadio, L., Delfosse, P., Tychon, B.: Brown rust disease control in winter wheat: I. Exploring an approach for disease progression based on night weather conditions. Environ. Sci. Pollution Res. 21(7), 4797-4808 (2014)

El Jarroudi, M., Kouadio, L., Beyer, M., Junk, J., Hoffmann, L., Tychon, B., et al.: Economics of a decision-support system for managing the main fungal diseases of winter wheat in the Grand-Duchy of Luxembourg. Field Crops Res. 172, 32-41 (2015) 
El Jarroudi, M., Kouadio, L., Bock, C.H., El Jarroudi, M., Junk, J., Pasquali, M., et al.: A threshold-based weather model for predicting stripe rust infection in winter wheat. Plant Dis. 101, 693-703 (2017)

El Jarroudi, M., Kouadio, L., Tychon, B., El Jarroudi, M., Junk, J., Bock, C., Delfosse, P.: Modeling the main fungal diseases of winter wheat: constraints and possible solutions. In: Kimatu, J.N. (ed.) Advances in Plant Pathology. IntechOpen (2018). https://doi.org/10.5772/ intechopen.75983

FAO: FAOSTAT. Crops, National Production. FAO, Rome, Italy (2018)

Ferentinos, K.P.: Deep learning models for plant disease detection and diagnosis. Comput. Electron. Agric. 145, 311-318 (2018)

Hovmoller, M.S., Justesen, A.F., Brown, J.K.M.: Clonality and long-distance migration of Puccinia striiformis f.sp. tritici in north-west Europe. Plant. Pathol. 51, 24-32 (2002)

Hovmøller, M.S., Walter, S., Bayles, R.A., Hubbard, A., Flath, K., Sommerfeldt, N., et al.: Replacement of the European wheat yellow rust population by new races from the centre of diversity in the near-Himalayan region. Plant Pathol. 65, 402-411 (2015)

Junk, J., Görgen, K., El Jarroudi, M., Delfosse, P., Pister, L., Hofmann, L.: Operational application and improvements of the disease risk forecast model PROCULTURE to optimize fungicides spray for the septoria leaf blotch disease in winter wheat in Luxembourg. Adv. Sci. Res. 2, 57-60 (2008)

Kranth, P.R.G., Lalitha, H.M., Basava, L., Mathur, A.: Plant disease prediction using machine learning algorithms. Int. J. Comput. Appl. 182(25), 1-7 (2018)

Lopez, G., Rubio, M.A., Martinez, M., Battles, M.: Estimation of hourly global photosynthetically active radiation using artificial neural network models. Agric. For. Meteorol. 107, 279291 (1998)

Lowe, A., Harrison, N., French, A.P.: Hyperspectral image analysis techniques for the detection and classification of the early onset of plant disease and stress. Plant Methods 13, 80 (2017). https://doi.org/10.1186/s13007-017-0233-z

Moreau, J.M., Maraite, H.: Integration of knowledge on wheat phenology and Septoria tritici epidemiology into a disease risk simulation model validated in Belgium. Asp. Appl. Biol. 55, $1-6$ (1999)

Moshou, D., Bravo, C., West, J., Wahlen, S., McCartney, A., Ramon, H.: Automatic detection of 'yellow rust' in wheat using reflectance measurements and neural networks. Comput. Electron. Agric. 44, 173-188 (2004)

Odilbekov, F., Armoniene, R., Henriksson, T., Chawade, A.: Proximal phenotyping and machine learning methods to identify Septoria tritici blotch disease symptoms in wheat. Front. Plant Sci. 9, 685 (2018). https://doi.org/10.3389/fpls.2018.00685

Prasad, S., Kumar, P.S., Ghosh, D.: An efficient low vision plant leaf shape identification system for smart phones. Multimedia Tools Appl. 76(5), 6915-6939 (2017)

Sache, I.: Short-distance dispersal of wheat rust spores by wind and rain. Agronomie 20, $757-$ 767 (2000)

Sperschneider, J.: Machine learning in plant-pathogen interactions: empowering biological predictions from field scale to genome scale. New Phytol. (2019). https://doi.org/10.1111/ nph. 15771

Te Beest, D.E., Paveley, N.D., Shaw, M.W., van den Bosch, F.: Disease-weather relationships for powdery mildew and yellow rust on winter wheat. Phytopathology 98, 609-617 (2008)

Verreet, J.A., Klink, H., Hoffmann, G.M.: Regional monitoring for disease prediction and optimization of plant protection measures: the IPM wheat model. Plant Dis. 84(8), 816-826 (2000) 
Wegulo, S.N., Zwingman, M.V., Breathnach, J.A., Baenziger, P.S.: Economic returns from fungicide application to control foliar fungal diseases in winter wheat. Crop Prot. 30(6), 685692 (2011)

Yang, X., Guo, T.: Machine learning in plant disease research. Eur. J. BioMed. Res. 3, 6-9 (2017)

Zadoks, J.C.: Yellow rust on wheat: studies in epidemiology and physiologic specialisation. Tijdschr. Planteziekten 67, 69-256 (1961) 